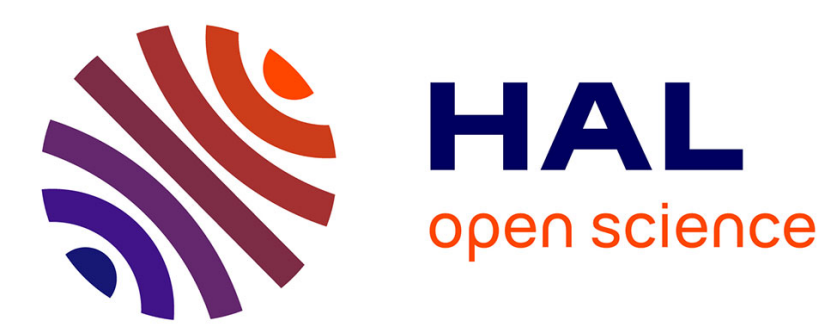

\title{
Electrocoalescence of water drops in oil shear flow: development of an experimental set up
}

\author{
Jonathan Raisin, Pierre Atten, Jean-Luc Reboud
}

\section{To cite this version:}

Jonathan Raisin, Pierre Atten, Jean-Luc Reboud. Electrocoalescence of water drops in oil shear flow: development of an experimental set up. ICDL 2011, Jun 2011, Trondheim, Norway. PID1762101.pdf. hal-00608047

\section{HAL Id: hal-00608047 \\ https://hal.science/hal-00608047}

Submitted on 12 Jul 2011

HAL is a multi-disciplinary open access archive for the deposit and dissemination of scientific research documents, whether they are published or not. The documents may come from teaching and research institutions in France or abroad, or from public or private research centers.
L'archive ouverte pluridisciplinaire HAL, est destinée au dépôt et à la diffusion de documents scientifiques de niveau recherche, publiés ou non, émanant des établissements d'enseignement et de recherche français ou étrangers, des laboratoires publics ou privés. 


\title{
Electrocoalescence of water drops in oil shear flow: development of an experimental set up
}

\author{
J. Raisin, J.-L. Reboud and P. Atten. \\ Grenoble Electrical Engineering laboratory (G2Elab) \\ CNRS, Grenoble INP \& Joseph Fourier University \\ Grenoble - France \\ jean-luc.reboud@grenoble.cnrs.fr
}

\begin{abstract}
Present research aims at determining the conditions leading to electrocoalescence of water drops in oil flows and at characterizing the interplay between fluid dynamics and electric field in the mechanism. We describe here the build-up of an experimental set-up designed to investigate the critical coalescence conditions in the case of two free water droplets in an oil shear flow under the action of an applied electric field. Drop pairs will be injected in a Poiseuille flow to study, by optical means, their relative motion, deformation and possible coalescence. Important part of this preliminary work concerns the injection of controlled charge free drop pairs using a newly developed EHD actuation technique. Second paper [1] deals with theoretical and numerical analyses in the same configuration.
\end{abstract}

Keywords-component; electrocoalescence, drop-on-demand

\section{INTRODUCTION}

Compact Electro Coalescers (CECs) are growingly used in the petroleum industry to separate water, coproduced during extraction and desalting operations, from the oil phase. Stateof-the-art CECs are in-line flow devices designed to increase the mean size of water droplets by merging and, therefore, to reduce the time required for their sedimentation under gravity. Though, the control and increase of their efficiency remain, to date, particularly challenging as the numerous phenomena involved in electrocoalescence are far from being fully understood. The present work is part of a collaborative research project "Electrocoalescence - Criteria for an efficient process in real crude oil systems"; coordinated by SINTEF Energy Research (Norway). G2Elab-CNRS aims at determining the conditions, especially the critical electric field, leading to electrocoalescence of drops in various configurations and at characterizing the interplay between fluid dynamics and electrostatic interactions in the mechanism.

In a CEC, electrocoalescence between drops is promoted by the combined action of the hydrodynamic and electric forces [2]. It involves the collision of two droplets and the thinning and rupture of the film of immiscible liquid separating their facing surfaces. Present work focuses on electrohydrodynamic interactions in simple flow of model liquids (i.e. two water droplets in a shear flow of insulating oil), as a necessary step prior to the analysis of such a phenomenon in turbulent flows of water in real crude oil emulsions [3]. Expected result is the validation and improvement of a criterion, formerly developed in [4], relating the time of close proximity of droplets in a

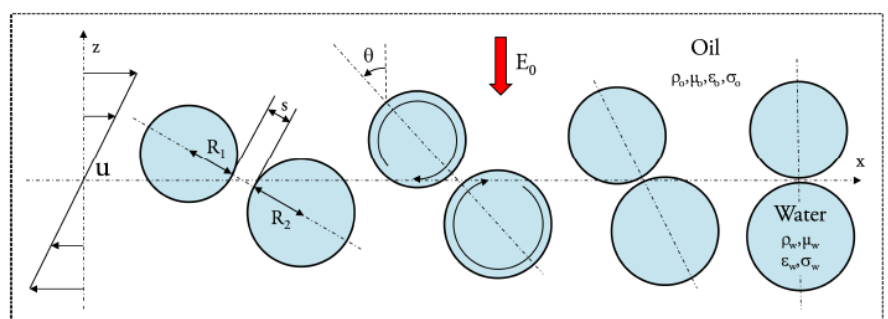

Figure 1: Schematic representation of the electrocoalescence mechanism in a state-of the-art dewatering device: water drops collide due to local shear flows inside the oil turbulent mainstream and then approach each other under the effect of strong electric attraction forces.

flowing emulsion and that required for the formed intervening film to thin down to its critical thickness, promoting the drops merging. The schematic picture retained for the process is the following (Fig. 1.): i) the approach of droplets (quasicollisions) is provided by the more or less turbulent flow, the electric forces playing but a negligible role; ii) if the droplets are close enough, their coalescence is induced by the action of the electric field, convection by the neighboring flow having a negligible influence in the last stages of thinning of the oil film between the droplets.

The phenomenon of film thinning between drops suspended in an immiscible liquid has been investigated in hydrodynamic and buoyant forces driven configurations [5] in which it represents the time-determining step of the whole coalescence process [6] and has a great impact on emulsions stability [7]. Different analytical expressions have thus been established depending on the nature and behavior of the interfaces. However, the characteristic properties and results found are not applicable to the electrocoalescence case because of the strongly different pressure distribution in the film induced by electric forces and of the absence of the dimple formation. Filling in this lack seemed therefore of primary importance while attempting to build a criterion, before, e.g., looking at the possible factors able to prevent the film rupture to occur (surfactants, trapping of solid particles, etc...).

The present paper focuses on the build-up of an experimental set-up (theoretical and numerical analyses are detailed in $[1,4])$ designed to investigate the critical conditions for the electrocoalescence of two free water droplets in an oil shear flow. We aim at presenting and explaining some of the

This work was funded by the project "Electrocoalescence - Criteria for an efficient process in real crude oil systems"; co-ordinated by SINTEF Energy Research. Contact person is L.E.Lundgaard. The project was supported by The Research Council of Norway, under the contract no: 169466/S30, and by the following industrial partners: Aker Solutions AS, BP Exploration Operating Company Ltd, Hamworthy Technology and Products AS, Shell Technology Norway AS, Petrobras, Saudi Aramco and Statoil ASA.). 
choices made throughout the building stage concerning the different functions. First task concerned the establishment of a Poiseuille oil flow and the implementation of an automated data acquisition system for the study, by optical means, of the droplets relative motion, deformation and possible coalescence. An important part of the work was devoted to the injection of controlled charge-free drop pairs in oil flow: the proposed method is based on a newly developed EHD actuation technique and results in a test configuration are presented.

\section{EXPERIMENTAL SET UP}

The design and assembly of an experimental setup allowing to study the electrocoalescence mechanism at the drop scale through all its different steps is proposed. Such a tool will be used to improve the relevance of the coalescence criterion [4] by both increasing the physical knowledge on previously neglected phenomena and quantify their respective influence. The experiment consists in the injection of two calibrated conducting water drops at relatively close positions inside a well-established shear flow of a dielectric liquid. Due to the spatial velocity gradients, as schematized on figure 1, the drop initially behind will chase the other and catch up in a region where a background electric field will be applied.

Polybutene oil (Ineos Oligomers - Indopol Grade L-6) was retained for the dielectric liquid phase. Such oil is transparent to visible light with a refractive index (1.461) different from that of water (1.333), non-drying, highly resistant to oxidation by UV and moderate heat, hydrophobic, and can easily be emulsified. It is also practically non-toxic, compatible with usual cell construction materials and can be washed efficiently through dilution in Cyclohexane. However, it exhibits a relatively strong dependency of viscosity with temperature and the observed decrease of its interfacial tension coefficient with the storage under ambient conditions might justify particular attention. Its main characteristics are given in table I.

In simple shear flows, two drops initially moving along close trajectories roll around one another and have a very small spacing during a finite time interval. From a practical viewpoint, many difficulties make a hypothetical set-up for a cylindrical Couette flow extremely complex to design so that a Poiseuille flow has been chosen as illustrated on figure 2 .

A first requirement is to obtain a steady and wellestablished oil Poiseuille flow. The dimensioning of the test cell taking into account the various constraints led to define a rectangular (Plexiglas) duct of thickness $2 \mathrm{~cm}$ and width $16 \mathrm{~cm}$ [4] The entrance section, $50 \mathrm{~cm}$ in length is devoted to the establishment of the Poiseuille profile for the oil of moderate

TABLE I. PROPERTIES OF PROPOSED MODEL LIQUIDS

\begin{tabular}{|c|c|c|}
\hline $\begin{array}{c}\text { Liquid } \\
\text { properties }\left(\mathbf{2 5}^{\circ} \mathbf{C}\right)\end{array}$ & Tap Water & Polybutene Oil \\
\hline Density $\left(\mathbf{k g . m}^{-3}\right) \boldsymbol{\rho}_{\mathbf{i}}$ & 1000 & 824 \\
\hline Viscosity $(\mathbf{P a . s}) \boldsymbol{\mu}_{\mathbf{i}}$ & 0.001 & 0.0102 \\
\hline $\begin{array}{c}\text { Interfacial Tension } \\
(\mathbf{m N} / \mathbf{m}) \boldsymbol{\gamma}\end{array}$ & \multicolumn{2}{|c|}{$18-25$} \\
\hline Relative Permittivity $\varepsilon_{\mathbf{r i}}$ & 80.1 & $2.2-2.3$ \\
\hline Conductivity $(\mathbf{S} / \mathbf{m}) \sigma_{\mathbf{i}}$ & $0.05-0.08$ & $\leq 6.710^{-13}$ \\
\hline
\end{tabular}

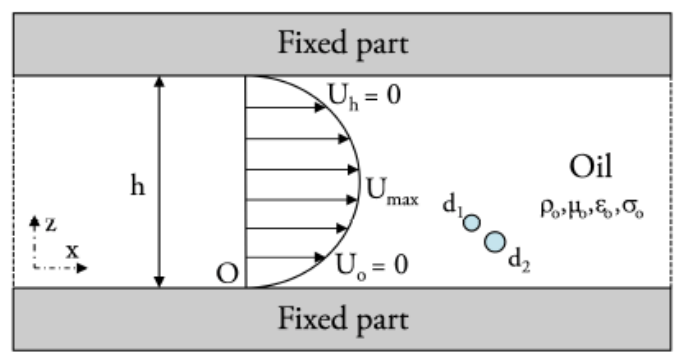

Figure 2: Scheme of oil Poiseuille flow and water droplets.

viscosity $(\sim 10 \mathrm{mPa} . \mathrm{s})$ and mean velocity $\mathrm{U} \sim 5 \mathrm{~cm} / \mathrm{s}$. The test section (60 cm long) includes the drop injection system and the zone subjected to a uniform electric field (figure 3 ). The whole cell is linked through $30 \mathrm{~mm}$ plastic corrugated tubes to upstream and downstream reservoirs. The latter, with opaque walls and containing up to 60 liters, allows to properly store all the oil during long pauses separating campaigns of experiments. It also features a drain system to dispose of the sedimented water droplets. The upstream reservoir is partially transparent and mounted on a vertical lifting table in order to visualize and position the liquid free surface. A magnetic pump (Iwaki - MD-55R-5) and an overflow are used to refill and maintain a constant free surface level. As a result from the generated height difference oil will flow at a stable rate, measured by an inline flow meter (Bürkert - S030/8035) and set to the desired value $\left(\mathrm{Q}=0.161 . \mathrm{s}^{-1}\right)$ by adjusting the upstream reservoir level.

Two electrically neutral water drops will be injected at given locations in the Poiseuille oil flow so that they become close when entering the steady electric field region, i.e. after traveling about $\mathrm{L} \sim 315 \mathrm{~mm}$. Owing to their small size, a very weak influence of gravity on their motion is to be expected. Therefore, drops with either even or slightly uneven radii will most likely follow parallel, nearly linear, flow path (e.g. a simple estimation using the terminal fall velocity under gravity for droplets of same radius $\mathrm{R}_{0}=25 \mu \mathrm{m}$ and velocity difference of $0.05 \mathrm{~m} . \mathrm{s}^{-1}$ predicts a vertical offset of about $0.315 \mathrm{~mm}$ at $\mathrm{L}$ $=315 \mathrm{~mm}$ ). Hence, collisions will occur for initial transversal separation $\Delta \mathrm{z}_{0}$ close to $\mathrm{R}_{1}+\mathrm{R}_{2}$ and will mainly depend on the initial longitudinal separation $\mathrm{x}_{0}$ and relative height in the shear flow $\mathrm{z}_{0} / \mathrm{h}$. Owing to preliminary calculations, the designed test section will allow studying drops with diameters ranging from 20 to $240 \mu \mathrm{m}$ by adjusting $\mathrm{x}_{0}$ and $\mathrm{z}_{0} / \mathrm{h}$ between $1-3 \mu \mathrm{mm}$ and $0.2-0.4$, respectively. As a consequence, the control of the

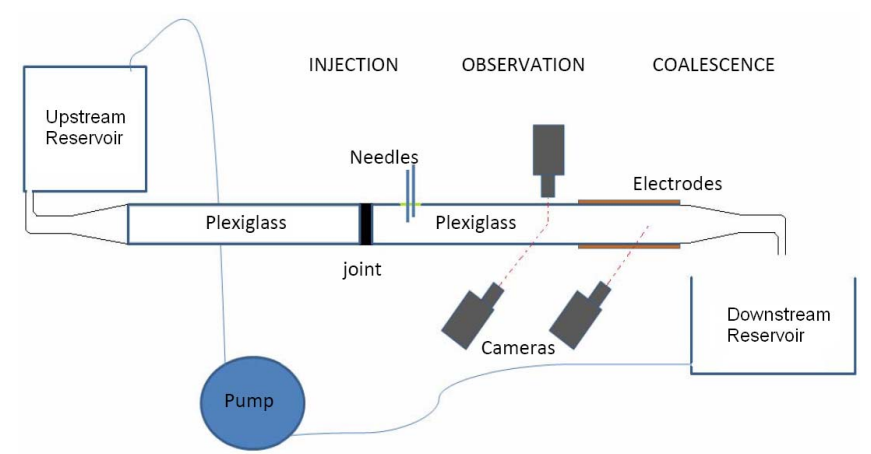

Figure 3: Schematic representation of experimental set-up 
location of injected droplets on the transverse axis is of primary importance. In order to cope for the limitations of existing actuation technique regarding those requirements, a a newly developed one will be detailed in the next section.

The second task includes the detection and characterization of the drops. The main visualization technique consists in recording pictures taken horizontally and vertically by two fully controllable CMOS cameras (Dalsa - Falcon 1.4M100, 100 fps, maximum resolution $(1400 \times 1024$ pixels $)$ and $\mathrm{PC}$ remote control ability) equipped with adequate lenses to focus on $1 \times 1 \mathrm{~mm}^{2}$ windows (five to twenty times the predefined drop diameters). Illumination is performed by two continuous/flashable LED light sources. The recording is triggered by the passage of the drops detected when they cross a laser beam. In-house programmed software of image treatment determines the drops diameter and their relative spatial positions. A third video camera is used to examine if coalescence occurred (one or two drops at the channel exit). For each experiment, eight parameters must be measured and stored: interfacial tension coefficient $\gamma$, oil viscosity $\mu_{\mathrm{o}}$ (from oil temperature measurement), background electric field type (AC sine/triangular/square or DC) and intensity E, undeformed drop radii $R_{1}$ and $R_{2}$ as well as the interfacial separation distance $s_{0}$ and angular offset $\theta$ when entering the coalescence region (see figure 1 ).

\section{DUAL WATER DROPS INJECTION IN OIL}

The crucial point in the experiment is the injection of electrically neutral water drops of controlled size at wellcontrolled locations. This will be performed through an inhouse developed electrical drop-on-demand technique adapted from a method proposed in 1993 for generating charged droplets $[8,9]$. As schematized on figure 4 , this on-demand EHD injection technique consists in the application of an electric field pulse to a meniscus of a conductive liquid immersed into a dielectric one. Due to the action of the induced electrostatic pressure, the water-oil interface, initially in equilibrium under the effects of gravity and capillary pressure,

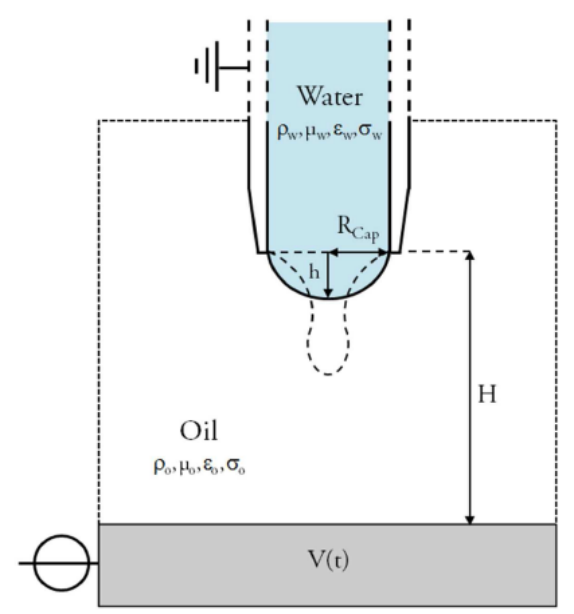

Figure 4: Electric field pulse based injection of a charge free water drop in oil from a meniscus. Geometry, in the meridian plane, and associated parameters.

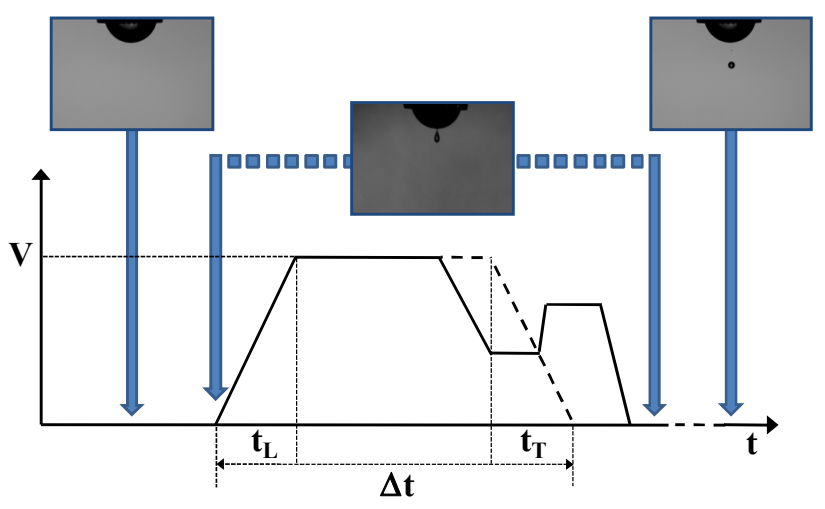

Figure 5: Temporal shape of the electrical pulses and associated image acquisition. Dashed and continuous curves stand respectively for Single and Multi-stage pulses.

deforms and eventually becomes unstable, leading to the release of one or more drops. However, to achieve the charge free condition, unlike referenced studies [8, 9], the electric pulse has to be finished before the last stage of the meniscus elongation, i.e. the appearance of a liquid filament between the drops and the meniscus and its break-up [10].

An extensive experimental study on the on-demand EHD injection of electrically neutral droplets has been performed using Single and Multi-stage electric pulses [10,11]. Different pulse shapes were tested and compared for different relative meniscus heights $\mathrm{h} / \mathrm{R}_{\text {Cap }}$, by varying the duration $\Delta t$, lead $t_{\mathrm{L}}$ and trail $t_{\mathrm{T}}$ times and amplitude $\mathrm{V}$ of their successive stages (figure 5). Two Multi-stage pulse $\left(\mathrm{MSP}_{2}\right.$ and $\left.\mathrm{MSP}_{6}\right)$ shapes were found to fulfill all the requirements: i) a large and continuous range of drop diameter can be produced (from less than $15 \mu \mathrm{m}$ up to more than $250 \mu \mathrm{m}$ ) from a given capillary radius $\mathrm{R}_{\text {cap }}=$ $230 \mu \mathrm{m}$ (single drop injections on Figure 7). ii) drops and satellites are obviously electrically neutral; iii) the injected drop trajectory is axial; iv) the technique is highly reproducible, the overall standard deviation being lower to 4 percent, as long as meniscus height differences along with changes in the liquids properties (temperature gradients, aging) are kept small. The range of obtainable diameter increases with the relative meniscus height $\mathrm{h} / \mathrm{R}_{\text {Cap }}[11]$.

Synchronized dual injections of either even or uneven water drops were then achieved with a multiple stage voltage pulse acting on two menisci with similar or different volume (or relative meniscus height) respectively. The menisci are at the

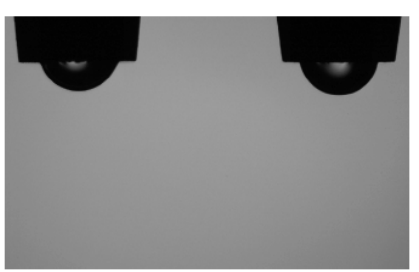

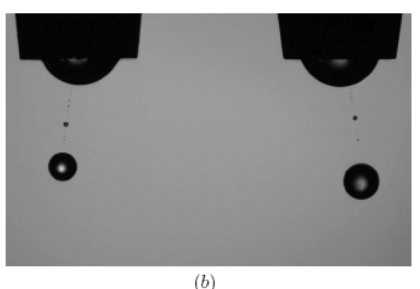

(b)
Figure 6: Synchronized injections of two electrically neutral uneven water drops in polybutene oil using $\mathrm{MSP}_{2}, \mathrm{~V}=3.80 \mathrm{kV}$. (a) Initial menisci with respective relative heights: left $\mathrm{h} / \mathrm{R}_{\text {Cap }}=0.74$, right $\mathrm{h} / \mathrm{R}_{\text {Cap }}=0.87$. (b) Released drops and satellites. Measured drops diameters and angular offsets: left drop diameter $=164.9 \mu \mathrm{m}$ and $\alpha=18^{\circ}$, right drop diameter $=$ $207.2 \mu \mathrm{m}$ and $\alpha=17$. 


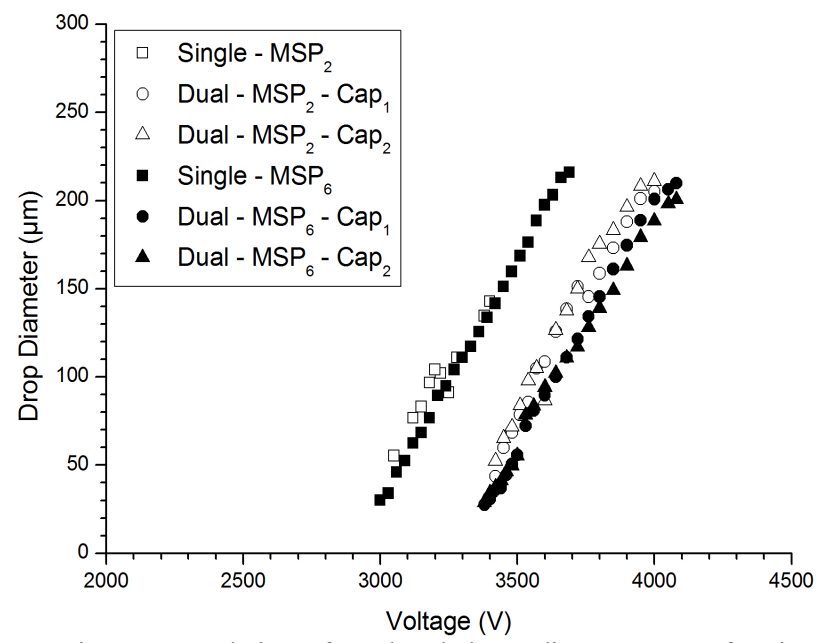

Figure 7: Evolution of produced drops diameters as a function of applied voltage in dual injections using two different MSPs. Comparison with single drop injections. Relative meniscus height $\mathrm{h} / \mathrm{RCap}=0.75$.

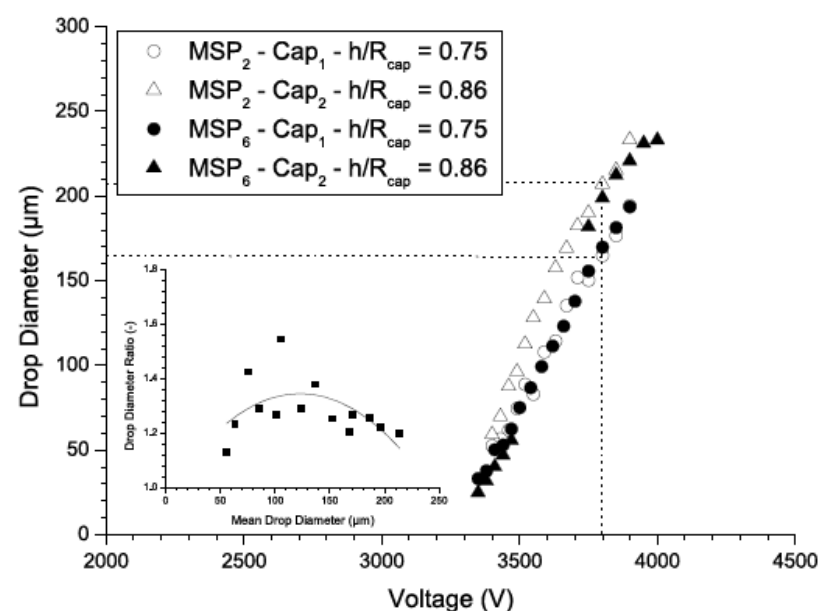

Figure 8: Variations of produced drops diameters and drop diameter ratio respectively as a function of applied voltage and mean drop diameter in dual injections using two different MSPs for relative meniscus heights $\mathrm{h} / \mathrm{R}_{\text {Cap }}=0.75$ and $\mathrm{h} / \mathrm{R}_{\text {Cap }}=0.86$. Dotted lines correspond to the experimental values deduced from the photograph of figure 6 .

extremity of two neighboring needles (Figure 6). Electrostatic interaction of the two needles induces decrease of electric field at the initial water-oil interface and small deviation from axial trajectory of the injected droplets. Results of dual injection of even droplets are compared with single injection cases in figure 7: the range of droplet diameters remains identical, given an offset of about $400 \mathrm{~V}$ is applied to the voltage in the case of dual injection. With uneven volumes of the two menisci, the developed DOD actuation technique is able to generate, simultaneously, two drops of different size, with a diameter ratio ranging up to 1.35 (photograph figure 6 and figure 8).

\section{CONCLUSION}

Design and assembly of an experimental setup achieved to study the complete electrocoalescence process between two calibrated charge free water drops injected in an oil shear flow is presented: a) a Poiseuille flow is generated in a narrow channel; b) two drops are injected in the flow and are subjected to an high electric field; c) a visualization technique is implemented to study their relative motion, deformation and possible coalescence.

As a key point of the experimental set-up, a dual drops injection system has been developed. It allows to generate simultaneously pairs of drops of even or uneven size with a very large range of diameter, by simply tuning two key parameters - the relative menisci height and applied voltage at the tip of neighboring needles - and fulfils all the requirements defined in the design of the experiment.

\section{REFERENCES}

[1] P. Atten, J. Raisin and J.-L. Reboud, 2011. Field induced coalescence of two free water drops in a viscous dielectric fluid, ICDL 2011, 26-30 june 2011,Trondheim, Norway

[2] L. Lundgaard, G. Berg, S. Ingebrigsten, P. Atten, 2006. Emulsions and emulsion stability. Vol. 132. CRC Press, Ch. Electrocoalescence for oilwater separation: fundamental aspects, pp. 549-592.

[3] Lesaint, C., Glomm, W. R., Lundgaard, L. E., Sjöblom, J., 2009, Dehydration efficiency of ac electrical fields on water-in-model-oil emulsions. Colloids and Surfaces A: Physicochemical and Engineering Aspects 352 (1-3), $63-69$.

[4] J. Raisin, 2011, Electrocoalescence in water-in-oil emulsions: towards an efficiency criterion, PHD report, April $8^{\text {th }}, 2011$, University of Grenoble, France.

[5] Liao, Y., Lucas, D., 2010. A literature review on mechanisms and models for the coalescence process of fluid particles. Chemical Engineering Science 65 (10), $2851-2864$.

[6] Rommel, W., Meon, W., Blass, E., 1992. Hydrodynamic modeling of droplet coalescence at liquid-liquid interfaces. Separation Science and Technology 27 (2), 129-159.

[7] Sanfeld, A., Steinchen, A., 2008. Emulsions stability, from dilute to dense emulsions - role of drops deformation. Advances in Colloid and Interface Science 140 (1), $1-65$.

[8] G. S. Wright, P. T. Krein and J. Chato, 1993 Self -Consistent Modeling of the Electrohydrodynamics of a conductive Meniscus, Conf. Rec. 1993 IEEE-IAS Annual Meeting, 93CH3366-2, pp. 1946-1955.

[9] G. S. Wright, P. T. Krein and J. Chato, 1993 Factors affecting dynamic electrical manipulation of menisci, IEEE Trans. Ind. Appl., vol. 29, no. 1, pp 103-112.

[10] J. Raisin, J-L. Reboud and P. Atten, 2009. An Experimental and Numerical Study on Electrically Neutral Drop-on-demand Ejection, Int. Symp. on Electrohydrodynamics, Malaysia, 25th-28th March 2009

[11] J. Raisin, P. Atten and J-L. Reboud, 2010. On demand EHD Injection of Electrically Neutral Water Droplets in Oil. 7th Conference of the French Society of Electrostatics SFE 2010, Montpellier, France, August 2010. 